\title{
The Electronic Book: Evolution or Revolution?
}

\author{
Elektronik Kitaplar: Evrim mi Devrim mi?
}

\section{Daniela ŽıVKOVIĆ}

\begin{abstract}
The aim of the paper is to show the most important developments of the e-book in the last 10 years. Special emphasis is on the activities contributing to the creation of favorable condition for the production, distribution and reading electronic books. Successful information management with regard to e-books means defining the term e-book itself, developing identification systems, digital rights management and legal deposit as a part of digital libraries and cultural heritage.
\end{abstract}

Keywords: E-book, Digital library, Electronic publishing, Legal deposit, Copyright.

Öz

Bu bildirinin amacı, elektronik kitaplarla ilgili son 10 yılın en önemli gelişmelerini incelemektir. Elektronik kitapların üretim, dağıtım ve okunması için gerekli koşulların yaratılmasına yardımcı olan etkinliklere özel önem verilmiştir. Elektronik kitaplarla ilgili başarılı bilgi yönetimi elektronik kitap teriminin tanımlanması, tanımlama sistemlerinin geliştirilmesi, sayısal hakların yönetimi ve sayısal kütüphaneler ve kültürel sistemin bir parçası olarak derleme yasasının geliştirilmesi anlamına gelmektedir.

Anahtar sözcükler: E-kitap, Dijital kütüphane, Elektronik yayıncılık, Derleme yasası, Telif hakkı.

\footnotetext{
* Bu makale "Değişen Dünyada Bilgi Yönetimi Sempozyumu, 24-26 Ekim 2007, Ankara."da bildiri olarak sunulmuştur.

"University of Zagreb, Faculty of Philosophy, Ivana Lučića 3, 10000 Zagreb, Croatia (daniela.zivkovic1@zg.htnet.hr).
} 


\section{Introduction}

At the turn of the twentieth to the twenty first century the exhibition "100 in 1000 - the most famous Croatian books of the last millennium" took place at the National and University Library in Zagreb, Croatia. The jury had a very difficult task to choose one hundred books from various fields of human knowledge published in the period of one thousand years which had an outstanding impact on the total life of the country representing cultural heritage. The chosen titles ranged from the handwritten books like De essentiis by Herman Dalmatinac published in 1143 to those printed at the end of the $20^{\text {th }}$ century. Browsing the catalog of the exhibition makes the reader wonder how many electronic books would be presented at such an exhibition at the turn of the next century or millennium.

For sure the first electronic books "electronic incunabula" did exist even before the introduction of the term "electronic book". There are some milestones in the infancy of electronic book production in general and in every country. The first electronic book in Croatia was published in 1995. It was the Bible (Živković, 2001a, 177-179; 2001b, 27).

Wilf Lancaster (1995) in his article "The Evolution of Electronic Publishing" mentioned that "electronic publishing can be considered to have evolved gradually over a period of about 30 years, passing through the following stages:

1. Use of computers to generate conventional print-on-paper publications.

2. The distribution of text in electronic form, where the electronic version is the exact equivalent of a paper version and may have been used to generate the paper version.

3. Distribution in electronic form only but with the publication being little more than print on paper displayed electronically. Nevertheless, it may have various 'value added' features. . . 
4. The generation of completely new publications that exploits the true capabilities of electronics."

Pettenati (2001) noticed that the very first electronic publication came in the 1980s in the form of plain text e-mails. They were sent to the subscriber via a mailing list. This kind of distribution was abandoned as soon as more effective media for publishing and distribution were introduced in the 1980s and 1990s.

In the years 1994-1995 the first electronic journals appeared. Web distribution started in 1995-1996. It was possible to use the rich format PDF, Portable Data Format, to embed links in the text and take the advantage of multimedia tools. It was not until 1999 that the electronic book began to gain more importance in the plans of publishers and in the holdings of libraries. Since then it has been an object of interest for publishers, librarians and book traders, and also of professionals outside the traditional book sector, information scientists and lawyers, who are trying to formulate the rules for its successful management. This has resulted in the pressing need to define the electronic book as precisely as possible. Moreover, considerations with regard to its typology, identification, digital rights management and depositing as a part of cultural heritage cover a considerable section of information management. The daily increasing number of new ebooks poses the question of their management. Are the numerous digital libraries real libraries or just collections of digital books?

\section{How to identify and define e-books?}

Even at the end of the twentieth century a book was still defined in accordance with the 1985 UNESCO recommendation as a "nonperiodic publication of at least 49 pages exclusive of the cover pages, published in a particular country and made available to the public". This definition was adopted in the ISO 9707:1991 with a note saying that "Within the ISBN system, books include microfilm and mixed media publications" (ISO 9707:1991).

In the age of intensified standardization it has become clear that the book, primarily a cultural asset, becomes a commodity when it receives its identifier ISBN (International Standard Book 
Number). Thus, it should be considered that the ISBN is the only practical parameter whose allocation defines the book not only in the practical but also in the theoretical sense, leading us to a practical definition of the electronic book. The author of this article carried out the first research into what the concept of a book covers in the above system (Živković, 2001a; 2005). There were several reasons for this approach. The ISBN is a distinct identifier that accompanies the book as a publishing product from its design until it reaches its reader. It was originally introduced in 1966 to identify the printed book and improve book management in an automated world, but in time it also began to be used for books that were not published on paper only. Its allocation is supervised by standardisation organizations and the ISO 2108 gives the principles and procedure for its use. The ISBN identifies a title or the edition of a title provided by a specific publisher at an international level, and it is unique to that particular edition (International Organization for Standards [ISO], 1992). One of the goals the system had to comply with was universality, and in 1974 it was clearly stated that the "International Standard Book Number is a universally accepted method of numerically designating books" (ISBN, 1974). Although this only referred to printed books at that time, publishers soon began to put out books in media that were not exclusively of paper. In 1978 the Panel proposed a revision of the ISO standard to define the book as "any medium intended to be read" (Advisory Panel, 1978, 4). Various other forms of nonbook material were officially included in the system in the following order: machine-readable tapes and multiple media (1975), video tapes, microfiche and films produced for educational purposes (1977), software (1983), audio books on cassettes (1986), machine-readable tapes and CD-ROM (1986). In 1993 the formulation began of Guidelines for allocating ISBNs to non-book material, and it was firmly decided that whereas ISBN allocation does not depend on the physical format of the book, the definition of electronic publications would have to include the requirement of public availability.

In 1999 a sample of 40 countries in four continents were surveyed to discover which publications in a particular country are 
allocated an ISBN. The author was the head of the Croatian ISBN Agency. She used a research sample of forty countries because in 1999 the national ISBN agencies of those countries submitted an annual report to the International ISBN Agency. Respondents from 27 countries filled out a questionnaire: Australia, Belgium, Bosnia and Herzegovina, Croatia, Cyprus, Czech Republic, Estonia, Finland, France, Germany, Hungary, Iran, Italy, Latvia, Lithuania, Luxembourg, Macedonia, Netherlands, New Zealand, Norway, Portugal, Russia, Slovakia, Slovenia, Sri Lanka, Sweden and the USA.

The results showed that all the sample countries allocate an ISBN to printed books, as the most widespread book form. Some countries also mark pamphlets but in doing so they use additional criteria besides the size of the publication, such as the quality of the text and pictures and the purpose of the pamphlet. Twenty out of 27 countries allocate an ISBN to mixed media publications, which shows that it has become customary to mark combinations of printed material and newer media. Fourteen countries mark educational videos and transparencies, 17 mark audio books on cassettes, 17 mark audio books on CDs, 16 mark software. Microfilm publications are allocated an ISBN in 16 countries, 21 countries mark CD-ROM and diskette publications, and 16 countries mark Internet publications. These results show that the number of publications that are considered to be "books" has increased and that in three decades the ISBN has grown from an identifier for the printed book to an identifier for a product of monographic character published in any medium (Živković, 2001a; 2005). This is completely consistent with the view that: "The medium is never of crucial importance. A product which by its content, periodical nature or purpose has the function of a book is suitable for being included in the system regardless of whether the medium is paper, fabric, animal skin, film, tape or disc" (Mollison, 1995).

The great spread of the ISBN system, which in 2001 had a membership of 560,000 publishers and in 2006 of 628,795 publishers from 218 countries worldwide, affected the traditional parameters defining the book, such as its size and medium. The 
firm boundary based on number of pages that differentiated between the book and the pamphlet has gradually disappeared and the emphasis is now laid on a work of monographic character with the function of a book published in any medium.

On the basis of the research described, it is possible to define the electronic book as a document of monographic character available to the public online or in physical form (on CDROM, DVD). In addition to text, it may include pictures and sounds, links with related online pages, and programmes to change and supplement it. The electronic book should have an ISBN, either as its only identifier or as part of the DOI (Digital Object Identifier) and URN (Uniform Resource Name) identifiers specific for electronic material. The electronic book may be available in various formats. The recommendation is for every format of the electronic book to have its own ISBN.

At the end of the $20^{\text {th }}$ century the electronic book was not present as a separate entry in reference works. Today's definitions mostly take into account the way of production and usage as follows (Reitz, 2007):

Electronic book. A digital version of a traditional print book designed to be read on a personal computer or an e-book reader (a software application for use on a standard-sized computer or a book-sized computer used solely as a reading device). Although the first hypertext novel was published in 1987 (Afternoon, A Story by Michael Joyce), electronic books did not capture public attention until the online publication of Stephen King's novella Riding the Bullet in March 2000. Within 24 hours, the text had been downloaded by 400,000 computer users. Some libraries offer access to electronic books through the online catalog. A universally accepted format and simple delivery system are needed. Synonymous with e-book, ebook, and online book.

One may wonder why typology of e-books at all? Models of electronic publishing are most frequently mentioned concerning journal publishing. In the course of bibliographic standardization 
IFLA developed the typology of e-resources distinguishing physical electronic books from online books in the nineties. Nowadays, the notion of electronic book becomes increasingly associated with the e-book published on the Internet rather than the physical one.

Another distinction is between the digitized e-books and digitally born books. In the evolution of the e-book the large digitization projects like Gutenberg, netLibrary.com, Google, Amazon, etc. play an important role in becoming milestones in ebook production. The Gutenberg Project was driven by the enthusiasm of the student Michael Hart in 1971 who was aware that the digital media and the Net offer an enormous possibility to distribute publications of various kinds. At the time when the Gutenberg Project was started there were as many as 100 users on the Net though it was obvious that Internet will connect the whole world one day. At the beginning just one printed book was copied manually a year. Today the project offers over 20,000 free e-books in the Project Gutenberg Online Book Catalog and about 3 million e-books are downloaded each month. Over the past 36 years it remained devoted to its primary aim to digitalize as many works from the public domain as possible and make them available free of charge (http://www.gutenberg.org). Unlike Gutenberg the commercial project netLibrary.com was launched by a number of businessmen from Colorado who started to digitalize and distribute copyrighted works over the Internet (http://netlibrary.com). They developed the Knowledge Station software that ensured charging for the access to e-books, as well as the protection of copyrighted material while being used by controlling duration of reading, the amount of copying and downloading of e-books. University libraries as the biggest buyers of books very soon accepted charging for using e-books. This way of management of digital rights gave an impetus to the spreading of e-books. Today netLibrary.com offers 130,000 e-book titles. Google has launched a program with a number of research libraries in the US and the UK aimed at ultimately scanning all the books in their collections. The result of this project would be a digital library of as many as 30 million volumes (Quint, 2004). 
Today, the majority of e-books present on the e-book market are digitized.

There were several attempts to count electronic books. There are more than fifty available formats of electronic books in the world. The book market in the USA has a total of 110,000 e-book titles, achieving 36 times the size of the German e-book market (Just, 2006). In June 2006, Springer launched a new platform with more than 10,000 e-book titles available at www.springerlink.com. In Nov. 2006 the purchase of e-books in the USA increased $9.2 \%$ as compared to Nov. 2005 (Verlage, 2007).

In the age of rationalization in the book market attempts have been made to develop the best standards for production of ebooks. Considerations are made on what kinds of paper books are suitable for translation into electronic form. Studies into the design, development, and evaluation of electronic books were done with the aim of helping designers and implementers to better integrate appearance and functional aspects of books into a more general methodology for the automatic production of electronic books for information access. The Visual Book project explored the importance of the visual component of the book metaphor in the production of "good" electronic books for referencing. The HyperTextBook project concentrated on the importance of models and techniques for the automatic production of functional electronic versions of textbooks (Crestani, Landoni and Melucci, 2005).

There are also some other standards to facilitate digital content creation, distribution and use by consumers. The International Digital Publishing Forum (IDPF) has just released a new standard for packaging a digital publication, including the contents of the publication, metadata, signatures, encryption, rights and other information into one standard file. Entitled "the Open eBook Publication Structure Container Format" (OCF), the new IDPF standard will allow publishers to release a single standard file into their sales and distribution channels and will also enable consumers to exchange unencrypted e-books and other digital publications between reading systems that support the new standard (New, 2006). In addition to this, e-books may be 
classified in the traditional way (like printed book) as handbooks, textbooks, literary works, etc. Textbooks are a very promising section of electronic publishing in which the appropriate ratio of text and illustrations should be found out.

The advantages and disadvantages of e-book readers (devices) have been discussed and development in this field may make the e-book more users friendly (Pietila, Timonen, Seisto and Nieminen, 2005).

The history of the ISBN - the international book numbering system - began at the end of 1965. Even at that time it was obvious that a unique and simple printed book identification number was a prerequisite for successful automation.

In the electronic environment it is even more important than in the traditional book sector to clearly define concepts such as publication, edition and publisher. Electronic trading demands standardized identification of items, especially those that are protected by copyright, and this includes the electronic book. Therefore the electronic book must clearly show who the publisher is, as the natural and legal person in charge of its publication and the investor in its production and distribution.

The speed with which electronic books can be electronically managed makes it important to recognize that a distributor becomes the publisher of a particular book, and may become part of the ISBN system, as soon as it acquires the copyright for that title. At the moment when an electronic book is identified as a publishing product the question necessarily arises of its edition.

An edition is a product of monographic character that includes sufficient contextual differences in relation to the same or similar contents with the same title, and it is the publisher who decides what these differences should consist of. A new edition is defined by: a) changes in format of the computer file, and/or b) changes of content exclusive of a new form of packaging and proof reading.

The online book is not associated with concepts such as copy, print and edition (in the sense of the total number of all the copies produced from one matrix) in the traditional meaning they 
have in publishing. On the other hand, for the electronic book in physical form these concepts have retained the same meaning as they have for the printed book.

The assignment of a unique ISBN to each format of an electronic book has called for the redefinition of the ISBN as a 13digit identifier, as is currently the case. The ISO addressed this matter in its new edition

ISO 2108:2005, Information and Documentation -International Standard Book Number (ISBN). This new fourth edition of ISO 2108 introduces the first major change in decades to the global ISBN system as it changes from a 10-digit to a 13-digit number. The revised ISBN standard specifies an implementation date of 1 January 2007 for the new 13-digit ISBN so that publishers, book retailers and libraries around the world can adapt their local systems and practices to the 13-digit ISBN.

Existing ISBNs is prefixed with the EAN (European Article Number) "bookland" prefix 978, bringing the ISBN into line with the EAN13 barcode number. On exhaustion of existing group prefixes, ISBNs will be allocated with the prefix 979. A separate identifier is required for each electronic version separately traded. ISBNs can be allocated to parts of books and e-books traded separately. Joint GS1 (EPC)/ISBN working group announced at Frankfurt Book Fair to agree standards for incorporating ISBN within EPC (Electronic Product Code). It will include publishers, booksellers and systems vendors.

Unlike the ISBN, the DOI and URN are identifiers used for managing electronic and other kind of material on the Internet. They are not only identifiers but they also provide resolution services. Both include the ISBN as a composite part when they are used to identify an electronic book. DOI registration agencies (DOI-RAs) already operated alongside the ISBN agencies in Germany (sub-agency of mEDRA), Italy (mEDRA), UK (Nielsen BookData) and US (Bowker) (International ISBN Agency, 2007). 


\section{Electronic Books as Legal Deposit}

Today the primary purpose of legal deposit is to preserve a nation's cultural heritage. Compilation of a national bibliography is hardly imaginable without legal deposit. The increasingly frequent situation, that certain contents are published only electronically, called for immediate revision of present laws so that in the future the total national publishing output of a country would be covered.

IFLA position on copyright in the digital environment (2000) points out that legislation should cover the legal deposit of electronic media. In the late nineties the electronic book as a legal deposit has posed a number of questions that should be answered by bibliographic centers in cooperation with publishers and legislators. Just to mention some of them: "What is a legal deposit for an e-book? Is it a deposit or is it privileged access negotiated by the user with the producer/publisher? Can legislation specify a right of use particular to the national agency in order to guarantee access and preservation, independent of commercial rights?" Following the model of the printed book, professionals in the book sector are expected to identify electronic books for legal deposit, to develop selection criteria, to archive books and to make them available to users. Bibliographic centers are expected to have a dominant role in this process, as already stated in the report on electronic publications by the European Commission as early as 1996 (Mackenzie, Owen and Wale, 1996).

Though in some countries the legal deposit law started to cover online publications quite early (Norway in 1989, Croatia and Denmark in 1998), the Conference of European National Librarians and Federation of European Publishers recommended voluntary deposit of electronic publications in 2000 . The reason for voluntary deposit was that at the turn of the century the methods of collecting online electronic publications were not developed, tested and generally accepted. In the meantime the situation has changed for the better and national bibliographic centers developed instructions for collecting electronic publications.

Commission Recommendation of 24 August 2006 on the digitization and online accessibility of cultural material and digital 
preservation points to the fact that "web harvesting is a new technique for collecting material from the Internet for preservation purposes. It involves mandated institutions actively collecting material instead of waiting for it to be deposited, thus minimising the administrative burden on producers of digital material, and national legislation should therefore make provision for it." It also recommends that the member states "make provision in their legislation for the preservation of web-content by mandated institutions using techniques for collecting material from the Internet such as web harvesting, in full respect of Community and international legislation on intellectual property rights". As web harvesting is necessarily not exhaustive for commercial publications some national bibliographic centers additionally rely on individual cooperation with electronic publishers to inform the center about the publication and allow its preservation and use on certain conditions.

The situation concerning legal deposit varies from country to country because it depends on special features of publishing. Despite the complex situation, three main approaches to the collection of electronic library materials exist:

1. Legal deposit laws cover offline electronic publications (e.g., Australia, Austria, France, Sweden, United Kingdom, USA);

2. Legal deposit laws cover both offline and online publications (e.g., Canada, Croatia, Denmark, Germany, Norway); and

3. Absence of any legal deposit law, so that libraries must negotiate with publishers on voluntary basis (e.g., Netherlands).

Some countries from the first group give instructions to their electronic publishers to submit information on electronic publications or publications themselves on a voluntary basis and develop some projects in this sense (e.g., Australia, Austria, United Kingdom). In Finland new Act on Legal Deposit is under preparation. It is expected to take effect in 2008. The amendment of the Copyright Act (effective from the beginning of 2006) gives the National Library the right to collect freely accessible online 
electronic materials and make these materials available to the public within the premises of the Library or other legal deposit libraries. On January 1, 2007, legal deposit legislation in Canada was extended to include the deposit of online publications (Guidelines, 2007). Among online publications that do not need to be deposited are databases. The author of this article discussed the relation of databases and electronic books (Živković, 2001a; 2005). Databases still remain the most complex questions of deposit because of digital rights management issues. Commission Recommendation of 24 August 2006 encourages effective collaboration between EU member states to avoid a wide variety of rules governing deposit of digital material. The development of these deposit rules and their effective application at the national level are the most objective criteria to measure considerable progress in e-book evolution.

\section{E-books as Intellectual Property}

Traditionally, libraries have been able to provide reasonable access to the purchased copies of copyright works held in their collections. Whereas the EU Directive on Copyright (2001) provides for limitations of rights in favor of public libraries and other institutions, in the case of online resources the obtaining of permission from a publisher is recommended. The electronic book thus requires awareness of copyright as a driving force in the book sector by establishing a legal framework for the operation of the electronic book business following the example of the printed book.

However, if in future all access and use of information in digital format becomes subject to payment, a library's ability to provide access to its users will be severely restricted. In order to maintain a balance between the interests of rights holders and users, IFLA has developed the IFLA position on copyright in the digital environment (2000). This is a set of exemptions to copyright protection that it considered reasonable and national legislation should take care of them. In the autumn of 2003 the new Croatian Copyright Law harmonized with the EU Directive on Copyright was adopted by the Parliament. 
Horvat (2005) noticed that for all candidate countries harmonization with the directive meant a general rise in the level of copyright protection. The bitter fight that EBLIDA led in the years preceding the enactment of the EU Directive on Copyright should be taken as a warning.

In line with the efforts of international organizations mentioned above and WIPO a legal framework for the electronic book has been created. As one or several computer datafiles ebooks are protected under Article 5 of the WIPO Copyright Treaty which protects collections of data or other material in any form which satisfies the selection or content criteria for intellectual creations. Article 4 of the same Treaty protects computer programmes regardless of their form or the manner of expression. For electronic books the right of access is essential which is regulated under Article 8 of the Treaty as the right of any communication to the public of works by wire or wireless means, including the making available to the public of works in such a way that members of the public may access these works from a place and at a time individually chosen by them. In the preamble of the Treaty the need to maintain a balance between the rights of authors and the larger public interest is recognized particularly with respect to education, research and access to information as reflected in the Berne Convention. In light of this, EU Directive additionally specifies limitations to the rights for the needs of persons with impaired hearing and poor sight for non-commercial purposes.

In the IFLA licensing principles set up by the Copyright and other Legal Matters Committee (CLM) in 2001 IFLA presents a set of 36 basic principles that should prevail in the contractual relationship between libraries and information providers. Due to digitization some segments of the e-book production will be subject to contracting between the author, publisher, distributor and libraries more often than before. Experts estimate that 80 percent of printed books in copyright fall into the orphan category. Commission of the European Communities recommends that member countries should improve conditions for digitization of, and online accessibility to, cultural material by creating mechanisms to facilitate the use of orphan works and promote the availability of 
lists of known orphan works and works in the public domain (Commission, 2006). The Creative Commons website (creativecommons.org) enables copyright holders to grant some of their rights to the public while retaining others through a variety of licensing and contract schemes including dedication to the public domain or open content licensing terms. The intention is to avoid the problems current copyright laws create for the sharing of information.

\section{Conclusion}

Compared with printed books, the history of the electronic book is very short. Yet, it is safe to say that thanks to making content of monographic character available on a digital medium and distributed via the Internet the electronic book means a revolution at the threshold of the third millennium. Over the past ten years different modes of production, distribution, usage and preservation of e-books were developed. Electronic books, mostly from the public domain, have increasingly become parts of today's digital and hybrid libraries mostly due to both numerous or large digitization projects and the activities of e-book publishers producing digitally born books. The technological advance has dematerialized the book. Most of the definitions or concepts relating to printed books have, after the appearance of digital medium, undergone some changes. An e-book cannot be associated with notions such as a copy or print run in the traditional sense of the word. As stated by IFLA, the usage of digital materials including e-books should not be different from that of analogue. The achievement of this goal poses a number of questions and tasks to be solved by librarians and other participants in the book sector. The Conference "Gutenberg's Heritage: the Electronic Book" held in April 2006 in Graz, Austria, put forward what e-books should really be in the future. They should be owned by the library and not just accessed by library users. They should be offered on the book market accompanied by added values such as catalog entries to ensure efficient bibliographic control. Librarians advocate the seamless use of digital library collections. The evolutionary side of the process over the past decade created legal framework for the e-book and paved to some extent the technological way for its deposit as cultural 
heritage in national bibliographic centers on the one hand and selection criteria on the other. EU urges member states to invest more money into research of technological development of ebooks (Framework Programme 7) and realization of digitization projects. Viviane Reding, Member of the European Commission responsible for Information Society and Media in her closing speech at the Conference on Scientific Publishing in the European Research Area "Access, Dissemination and Preservation in the Digital Age" in Brussels on February 16, 2007, said:

Research on digital preservation will also be enhanced, and some 25 million euro has been earmarked to this end within the ICT-programme for the years 2007 and 2008. 10 more million euro will be dedicated to a better accessibility and usability of scientific information through the eContentplus programme. The Commission will also take a more pro-active role in the discussions between stakeholders and try to bring them closer together. One forum for these discussions is the high level group on digital libraries, where I listen to all views with the greatest attention.

The issue of the electronic book and digital libraries has been increasingly present in the LIS curricula (for example, at the Department of Library Science, University of Zagreb, Croatia, since 2000).

Having traditional functions of a library in mind, one should notice that via Internet digital collections of e-books rather than real digital libraries are available. Therefore evolution is still expected to continue in the years to come because more efficient ways to distribute, use and preserve e-books should be found out. Let us hope that in the next decade e-book will continue to enhance its quality and quantity, giving more emphasis to its content accessible online. The real speed at which evolution takes place is to be measured by the number of commercially distributed copyrighted e-books present in digital libraries of the future. Because, as stated by Michael Gorman (2003, 3):

We are merely at a given point in the steady evolution of libraries and human communication, with much change 
behind us and much change yet to come. Given that understanding, we as a profession can relax and deal with our problems coolly and on the basis of analysis and logic - evolutionary times call for evolutionary responses. The chief evolutionary response is, of course, the incorporation of computer technology and digital communication into library services in a balanced and practical way. To take the opposite view is to proclaim a revolution calling for nothing less than the overthrow of all existing structures.

\section{References}

Advisory Panel. (1978). ISBN Review, 2. 4.

Commission Recommendation of 24 August 2006 on the digitisation and online accessibility of cultural material and digital preservation. (2006). Brussels: Commission of the European Communities.

Crestani, F., Landoni, M., and Melucci, M. (2006). Appearance and functionality of electronic books. International Journal on Digital Libraries, 6(2):192-209.

Directive 2001/29/EC of the European Parliament and of the Council of May 222001 on the harmonisation of certain aspects of copyright and related rights in the information society. Retrieved May 13, 2006 from http://www.ivir.nl/ legislation/eu/copyright-directive.doc

Gorman, M. (2003). The enduring library: technology, tradition, and the quest for balance. Chicago: American Library Association.

Guidelines for legal deposit procedures for online publications. (2007). Retrieved on May 13, 2007 from http://www. collectionscanada.ca/electroniccollection/003008-1000-e.html

Horvat, A. (2005). Libraries as protectors of copyright and providers of free access to information. In S. Dragojević et al. (Eds.), Round Table Meeting eCulture: the European perspective cultural policy, creative industries, information lag (pp. 123-129). Zagreb: Institute for International Relations. 
IFLA licensing principles. (2001). Retrieved December 21, 2006 from http://www.ifla.org.

IFLA position on copyright in the digital environment. (2000). Retrieved December 20, 2006 from http://www.ifla.org

International ISBN Agency. (2007). Retrieved from http://www.isbn-international.org/

ISBN system. (1974). Berlin: International ISBN Agency.

International Organization for Standards. (1992).

ISO 2108 1992-05-15. Information and documentation. International Standard Book Numbering (ISBN) ( $3^{\text {rd }}$ ed.). Genève: ISO.

ISO 9707:1991. Information and documentation. Statistics on production and distribution of books, newspapers, periodicals and electronic publications. Genève: ISO. Retrieved August 2004 from htttp://www.iso.org.

Just, P. (2006). E-books für Bibliotheken: Eine Bestandsanalyse. Berlin: BibSpider.

Kadlecova, I., and Simon, E. (2003). Electronical information: The role of consortia in organizing knowledge. Berlin: BibSpider.

Lancaster, W. (1995). The evolution of electronic publishing Library Trends, 43(4), 518-527. Retrieved July 2007 from http://findarticles.com

Mackenzie Owen, J.S., and Wale, J.v.d. (1996). Deposit collections of electronic publications. Luxembourg: European Commission.

Mollison, A. (1995). Notes on the allocation of ISBNs to nonprinted books. ISBN Review, 16, 87-92.

New digital book standard released. (2006). International Digital Publishing Forum. Retrieved November 10, 2006 from http:// www.idpf.org/pressroom/pressreleases/ocf1.0.htm 
Quint, B. (2004). Google and research libraries launch massive digitization project. Retrieved July 17, 2007 from http://newsbreaks.infotoday.com/nbreader.asp?ArticlelD=16307.

Pettenati, C. (2001). Electronic publishing at the end of 2001. Retrieved November 30, 2006 from http://villaolmo.mib.infn.it/ Manuscripts/10_generalities/pettenati.pdf

Pietilä, K., Timonen, S., Seisto, A., and Nieminen, S. (2005). Reading with eBooks. In N. Enlund, and M. Lovreček (Eds.), Digitalisation and print media: Proceedings of the $32^{\text {nd }}$ International Research Conference of larigai 4-7 September 2005, larigai, Espoo (pp. 1726). Zagreb: Acta Graphica Publishers.

Reding, V. (2007). Scientific information in the digital age: How accessible should publicly funded research be? Speech delivered at Conference on Scientific Publishing in the European Research Area Access, Dissemination and Preservation in the Digital Age. Brussels, 16 February 2007. Retrieved July 17, 2007 from http://ec.europa.eu/research/ science-society/page_en.cfm?id=3459

Reitz, J.M. (2007). ODLIS: online dictionary of library and information science. Retrieved July 17, 2007 from http://lu.com/odlis/search.cfm

Unesco revised recommendations concerning the international standardization of statistics on the production and distribution of books, newspapers and periodicals. (1985). Paris: Unesco.

Verlage auch ohne Potter auf Vorjahrsniveau. (2007). BörsenblattNewsletter, 11.2.2007. Retrieved July 17, 2007 from http://www.boersenblatt.net/136460/template/b3_tpl_suche_detail/

Živković, D. (2001a). Elektronička knjiga. Zagreb : Multigraf.

Živković, D. (2001b). Recent trends and developments in publishing in Croatia. Slavic and East European Information Resources, 2(3/4), 13-50.

Živković, D. (2005). The electronic book: the change of paradigm for a changing bookmarket. Berlin: BibSpider. 